\title{
Thermal Optimization and Assessment of a Long Duration Cryogenic Propellant Depot
}

\author{
Ryan Honour ${ }^{1}$ and Robert Kwas ${ }^{2}$ \\ ANALEX, Kennedy Space Center, FL 32899 \\ Gary O'Neil ${ }^{3}$ \\ NASA, Kennedy Space Center, FL 32899 \\ and \\ Bernard Kutter ${ }^{4}$ \\ United Launch Alliance
}

\begin{abstract}
A Cryogenic Propellant Depot (CPD) operating in Low Earth Orbit (LEO) could provide many near term benefits to NASA space exploration efforts. These benefits include elongation/extension of spacecraft missions and reduction of launch vehicle up-mass requirements. Some of the challenges include controlling cryogenic propellant evaporation and managing the high costs and long schedules associated with new spacecraft hardware development. This paper describes a conceptual CPD design that is thermally optimized to achieve extremely low propellant boil-off rates. The CPD design is based on existing launch vehicle architecture, and its thermal optimization is achieved using current passive thermal control technology. Results from an integrated thermal model are presented showing that this conceptual CPD design can achieve propellant boil-off rates well under $0.05 \%$ per day, even when subjected to the LEO thermal environment.
\end{abstract}

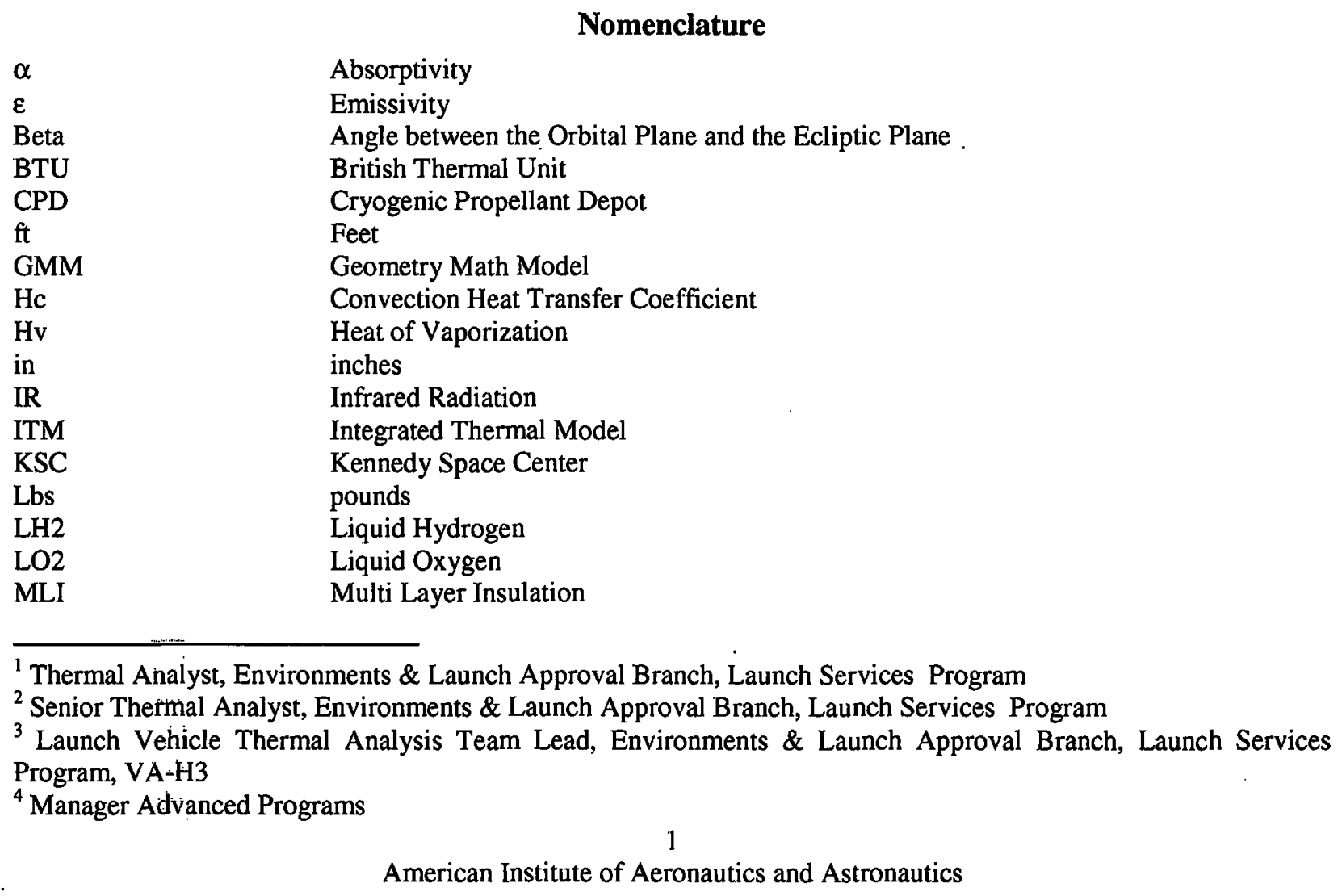




$\begin{array}{ll}\text { mT } & \text { Metric Ton } \\ \text { nm } & \text { Nautical Mile } \\ \text { PSI } & \text { Pound per Square Inch } \\ \text { Q } & \text { Average Heat Leak Rate } \\ \text { RAAN } & \text { Right Ascension of Ascending Node } \\ \text { RadK } & \text { Radiation Conductor } \\ \text { Theta } & \text { Angle between the CPD Minor Axis and the Ecliptic Plane }\end{array}$

\section{Introduction}

long duration CPD is a conceptual vehicle that can store large quantities of cryogenic propellant in space for extended periods. A CPD would function as an on-orbit refueling station for in situ spacecraft and/or launch

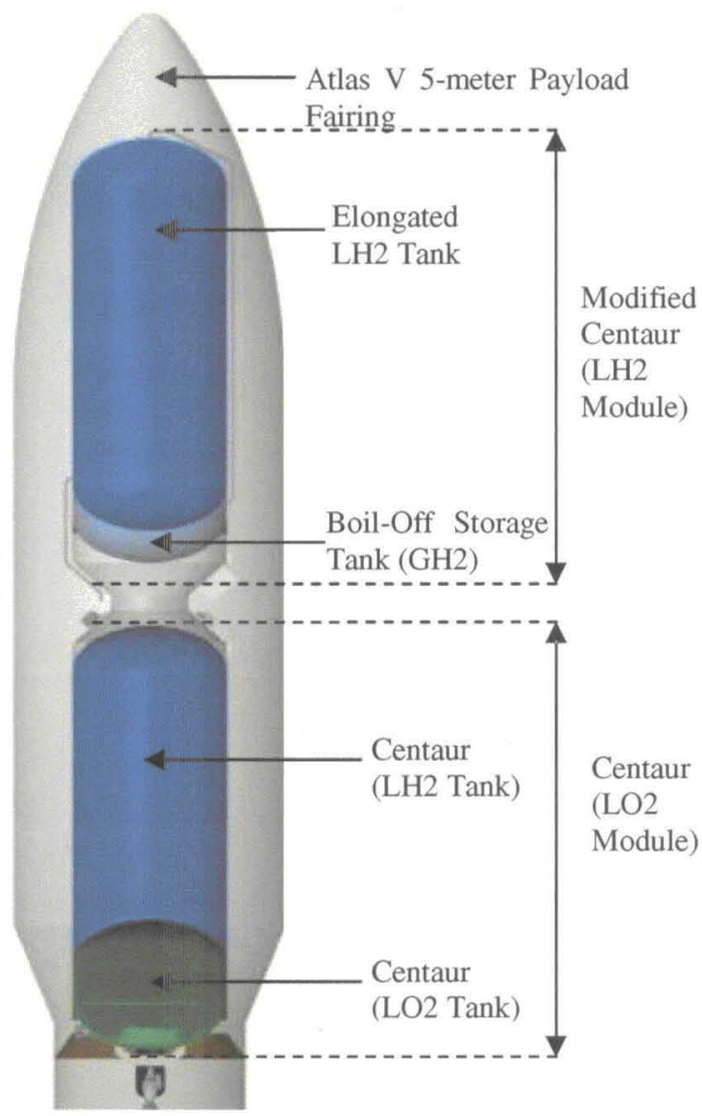

Figure 1. Cryogenic Propellant Depot Concept (Launch Configuration) vehicles. A CPD could potentially provide many benefits to the NASA space exploration program including the extension/elongation of spacecraft missions and reduction of launch vehicle up mass requirements. As shown in Fig. 1, the $\mathrm{CPD}$ concept considered in this analysis was a dual propellant storage configuration, which is based on the current Atlas V Centaur design. In this CPD concept, the forward end of an Atlas V Centaur is mated to the aft end of a modified Atlas V Centaur. The modified Centaur would consist of an elongated LH2 tank connected to a small boil-off storage tank. Both the Centaur and modified Centaur would be encapsulated within the Atlas V 5-meter payload fairing at launch. Once on orbit, residual LH2 within Centaur would be transferred to the modified Centaur; the residual $\mathrm{H} 2$ would be purged with Helium. The Centaur would then be refilled, onorbit, with LO2. Consequently, the modified Centaur functions as the on-orbit LH2 storage module, and the Centaur functions as the on-orbit $\mathrm{LO} 2$ storage module. The dual propellant CPD concept has the advantage of being able to store both LH2 and LO2. Further, the concept utilizes existing, or slightly modified, flight hardware. To achieve its target boil-off rate, the CPD will need to store cryogenic propellant for extended periods with minimal evaporative losses. This will require, in part, a Thermal Protection System (TPS) specifically designed to minimize the cryogenic propellant boil-off associated with each module. Aside from the TPS design, the orbit in which the CPD flies will also play an important role in determining the propellant boil-off rate. From a logistics standpoint, LEO represents the most desirable orbit in which to fly the CPD. LEO would provide easy access for both on-orbit refueling and CPD maintenance/resupply. Conversely, LEO represents the least desirable orbit from a thermal management standpoint. Having significant amounts of solar, abedo, and earth IR, LEO constitutes the most severe on-orbit thermal environment and, undoubtedly, would be the most challenging orbit from which to manage cryogenic propellant boil-off. Because it is both logistically desirable and thermally challenging, LEO was considered to be the ideal orbit to investigate in this analysis. It was felt that a CPD design that could achieve the desired boil-off rate in LEO could also achieve, or exceed, this boil-off rate in higher, less thermally severe, earth orbits (i.e., geosynchronous, Lagrangian, etc.). In this sense, LEO provides the ultimate test of CPD storage capabilities. 


\section{Development of the CPD ITM}

The CPD ITM was developed in Thermal Desktop ${ }^{\top M}$ Version 5.3. Thermal Desktop ${ }^{\top M}$ is a thermal analysis tool that facilitates the development of sophisticated computer aided design based thermal models. The development process involves generation of a Geometric Math Model (GMM) using the Thermal Desktop ${ }^{\text {TM }}$ built-in AutoCAD tool. Thermal and optical properties are assigned to the GMM using the Thermal Desktop ${ }^{T M}$ property edit forms. 'The Thermal Desktop ${ }^{\mathrm{TM}}$ pre-processor is used to compile the above data into a Systems Improved Numerical Differencing Analyzer (SINDA) thermal network. Radiation conductors are added to the SINDA thermal network using Thermal Desktop's ${ }^{\mathrm{TM}}$ radiation analyzer tool, RadCAD ${ }^{\mathrm{TM}}$. The combined RadCAD ${ }^{\mathrm{TM}}$ - SINDA thermal network can be solved using any of the various Thermal Desktop ${ }^{T M}$ built-in numerical solvers. The CPD ITM developed for this analysis consists of the CPD structures, cryogenic propellant, and on-orbit thermal environment. Development of the CPD ITM is described in detail in the following sections.

\section{A. On Orbit Thermal Environment}

As previously stated, the CPD was assumed to be in LEO for this analysis. The LEO thermal environment consists of the following heating parameters: 1) solar radiation, 2) albedo, 3) earth IR and, 4) deep space IR. Table 1 summarizes the specific values used for the LEO heating parameters. ' For this analysis, the CPD was assumed to be in a circular orbit (i.e., orbital eccentricity equals zero) in which the Right Ascension of the Ascending Node (RAAN) was always equal to $90^{\circ}$ (i.e., orbital procession rate equals zero). These simplifying assumptions ensure that the solar angle (beta) will always be equal to the orbital inclination and, further, that the radiant flux incident on the CPD will be constant as a function of orbital cycle. Table 1 summarizes the specific values used for the CPD orbital parameters.

Table 1. Summary of CDP Orbital Parameters

\begin{tabular}{|c|c|c|c|c|c|c|}
\hline $\begin{array}{c}\text { Altitude } \\
(\mathbf{n m})\end{array}$ & $\begin{array}{c}\text { Beta Angle } \\
\text { (degrees) }\end{array}$ & $\begin{array}{c}\text { RAAN } \\
\text { (degrees) }\end{array}$ & $\begin{array}{c}\text { Orbital Period } \\
(\mathbf{h r})\end{array}$ & $\begin{array}{c}\text { Orbital } \\
\text { Eccentricity }\end{array}$ & $\begin{array}{c}\text { Theta } \\
\text { (degrees) }^{\mathbf{5}}\end{array}$ & Tracking \\
\hline 365 & $0-30$ & 90 & 1.6378 & 0 & $-10-+10$ & $+Z$ Solar \\
\hline
\end{tabular}

The attitude of the CPD is defined in Table 1 and Fig. 2. The basic criteria for the designing the CPD attitude was to try to minimize the amount of orbital flux that can reach the CPD tanks. Preliminary analysis indicated that this could best be achieved by orientating the CPD such that its primary axis was perpendicular to the ecliptic plane and, further, to select beta angles that would protect the aft end of the LH2 module from incoming albedo and earth IR. Orientating the CPD such that its primary axis is perpendicular to the ecliptic plane ensures that the aft end of each storage module ( $\mathrm{LO} 2$ and $\mathrm{LH} 2$ ) has a constant view of deep space. Further, this attitude minimizes the amount of direct solar radiation that can reach the propellant tanks. However, earth IR and albedo can still be problematic for this attitude. As both are emitted diffusely, significant amounts of earth IR and albedo can traverse the open end of each sunshield and, subsequently, impinge upon the propellant tanks. Preliminary analysis suggested that the LH2 module was particularly sensitive to earth IR and albedo during the illumination phase of the orbit. To mitigate this impact, beta angles were chosen such that, during illumination, the open end of the LH2 module sunshield faced away from the incoming earth IR and albedo. While this orientation minimizes the amount of earth IR and albedo incident on the LH2 module during illumination, it has the opposite effect during eclipse. Fortunately, both the albedo and earth IR flux are very low during the eclipse portion of the orbit.

Within Thermal Desktop, the CPD orbit was simulated by using 18 discrete steady-state orbital positions. To simulate the on-orbit radiation exchange, 5000 rays per node were shot to calculate the CPD radiation conductors (RadK's) and orbital heating rates (solar, earth IR and albedo). A sensitivity study determined that further increasing the number of rays and/or orbital positions had little effect on the fidelity of the solution. It is important to note that all predicted heating rates in this analysis represent orbital averages (average from all eighteen orbital positions).

\footnotetext{
${ }^{5}$ Theta is the angle between the CPD minor axes and ecliptic plane (see Fig. 1).
} 
Table 2. Summary of LEO Thermal Environment

\begin{tabular}{|c|c|c|c|c|}
\hline \multirow{2}{*}{$\begin{array}{c}\text { Solar Radiation } \\
\left(\mathbf{B T U} / \mathrm{hr}^{\prime} / \mathrm{ft}^{2} /{ }^{\circ} \mathbf{F}\right)\end{array}$} & \multicolumn{2}{|c|}{ Earth IR $\left(\mathbf{B T U} / \mathrm{hr} / \mathrm{ft}^{2} /{ }^{\circ} \mathbf{F}\right)$} & \multirow{2}{*}{ Albedo } & $\begin{array}{c}\text { Deep Space } \\
\text { IR } \\
\text { (deg R) }\end{array}$ \\
\cline { 2 - 3 } & Illumination & Ellipse & & 4 \\
\hline 429.2 & 70.2 & 35.1 & 0.35 & 4 \\
\hline
\end{tabular}

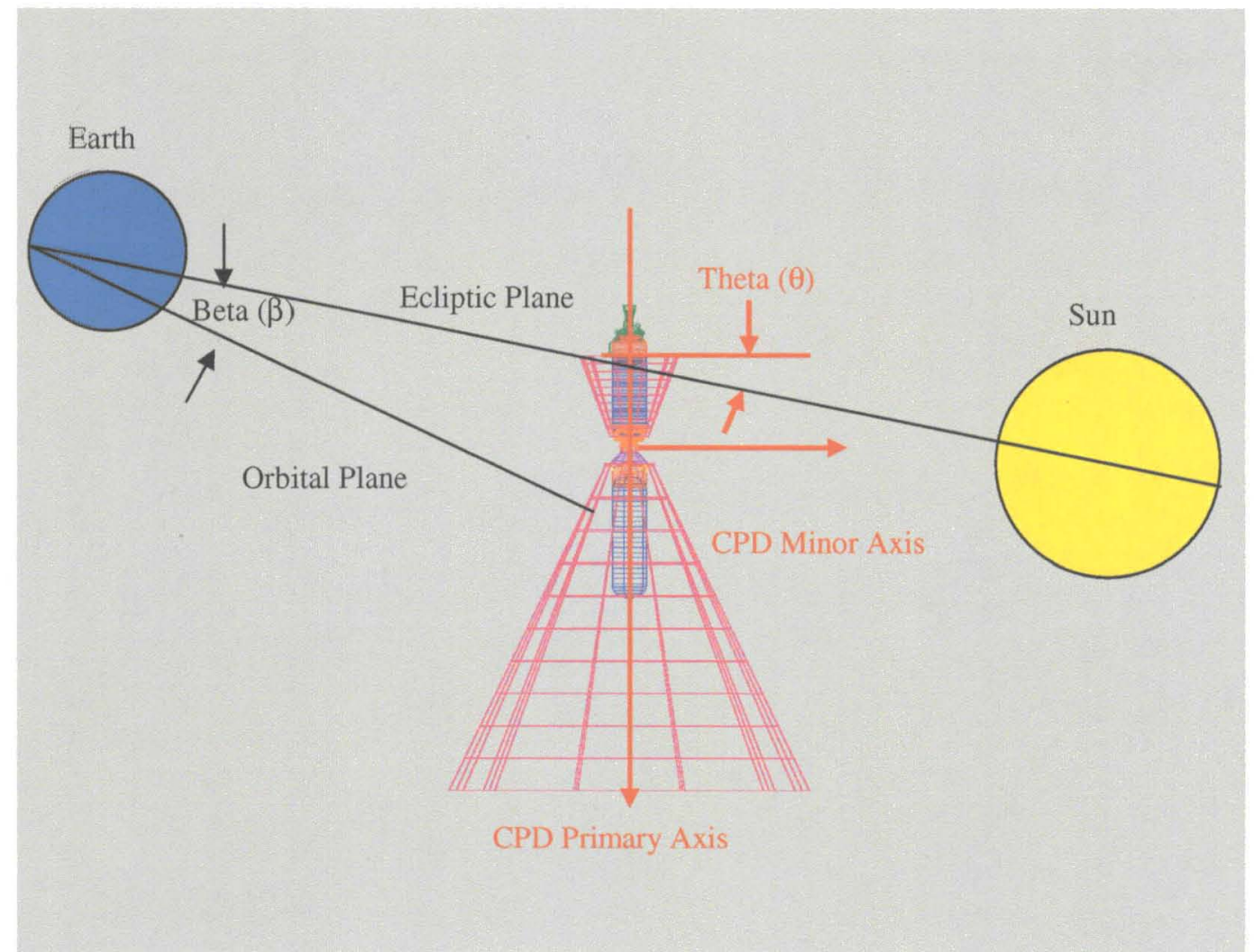

Figure 2. CPD Concept - Dual Propellant Storage Configuration (Broadside Vertical Attitude)

\section{B. Structures}

As shown in Fig. 3, the dual propellant CPD concept utilizes two separate modules to store cryogenic propellant onorbit: the LH2 module and LO2 module. The LO2 module is based on an Atlas V Centaur design. The LH2 module is based on a modified Atlas V Centaur design. To thermally isolate the two cryogenic propellants, the LH2 and LO2 modules are separated by three pairs of composite struts. ${ }^{7}$ The CPD is launched from inside an Atlas V 5meter fairing. To save weight, the LH2 module is launched without propellant. Once the CPD is on orbit, the remaining LH2 in the Centaur LH2 tank is transferred to the empty LH2 tank in the modified Centaur. After the LH2 transfer is complete, the remaining LO2 in the Centaur LO2 tank is transferred to the Centaur LH2 tank. Thus, the Centaur LH2 tank functions as an on-orbit LO2 storage tank. Further, the Centaur LO2 tank functions as an onorbit GO2 storage tank, collecting boil-off from the Centaur LO2 storage tank ${ }^{6}$. The GO2 could be used to collect heat from the CPD structure and dissipate the heat back out to space. For this report it was assumed that the avionics boxes and batteries on the Block II avionics shelf were powered off, and the RL-10 was not operating. During on-orbit steady state operation, use of avionics and batteries would be kept to a minimum in order to reduce the amount of latent heat generation.

\footnotetext{
${ }^{6}$ Note that in Fig. 3 and Fig. 4, the Centaur tanks are referred to by their on-orbit storage function.
} 
Once on orbit, the CPD sun shields are deployed. As shown in Fig. 4, the LH2 module is fully enclosed by its sun shield; however, the LO2 module is only partially enclosed by its sun shield. This is due to the fact that, in order to mitigate plume heating from the Centaur Reaction Control System (RCS), the maximum length of the LO2 module sunshield is limited to just 24.55 feet. $^{8}$ Because it is fully enclosed by its sun shield, the LH2 module is primarily an IR and albedo dominant radiation environment (i.e., virtually no direct solar). The optical properties for the exterior surfaces of the LH2 and the GH2 tanks were chosen as to have low alpha and very low emissivity values. These " optical properties enable the exterior surfaces of the $\mathrm{LH} 2$ and GH2 tanks to effectively reflect incident albedo and earth IR back to space. Because it is not fully enclosed by its sunshield, the LO2 module is subjected to much higher amounts of solar flux. Consequently, the optical properties for the $\mathrm{LO} 2$ and GO2 tanks were selected as to have low alpha values and high emissivity values (i.e., low $\alpha / \varepsilon$ ratio). These optical properties allow the LO2 and GO2 tank to effectively reflect incident solar radiation back to space, and effectively re-emit radiation in the IR spectrum. In̈ order to protect the CPD from the LEO radiation environment, all propellant tanks were enclosed in ten layers of MLI. Due to its very low emissivity, aluminized Kapton@ was selected as the optical coating for all MLI internal layers. ${ }^{5}$ This selection takes advantage of the fact that MLI internal layers participate only in IR exchange (i.e., absorptivity is not important for MLI internal layers).

Table 2. Optical Properties for LO2 Module Sun Shield

\begin{tabular}{|c|c|c|c|}
\hline Structure/Equipment Item & Material & Absorptivity/Emissivity & Ref. \\
\hline \multicolumn{4}{|l|}{ Centaur Sun Shield ${ }^{7}$} \\
\hline Sun Shield Layèr \#1 & $\begin{array}{ll}\text { Inner: } & \text { VDA Kapton® } \\
\text { Outer: } & \text { Silver Teflon® }\end{array}$ & $\begin{array}{ll}\text { Inner: } & 0.14 / 0.05 \\
\text { Outer: } & 0.07 / 0.80\end{array}$ & {$[4]$} \\
\hline Sun Shield Layer \#2 & $\begin{array}{ll}\text { Inner. } & \text { VDA Kapton@ } \\
\text { Outer: } & \text { SV5 }\end{array}$ & $\begin{array}{ll}\text { Inner: } & 0.14 / 0.05 \\
\text { Outer: } & 0.08 / 0.81\end{array}$ & {$[4]$} \\
\hline Sun Shield Layer \#3 & $\begin{array}{ll}\text { Inner. } & \text { VDA Kapton@ } \\
\text { Outer. } & \text { SV5 }\end{array}$ & $\begin{array}{ll}\text { Inner: } & 0.14 / 0.05 \\
\text { Outer: } & 0.08 / 0.81\end{array}$ & {$[4]$} \\
\hline \multicolumn{4}{|l|}{ Primary Propellant Tank } \\
\hline Sun Shield Layer \#1 & $\begin{array}{ll}\text { Inner, } & \text { VDA Kapton@ } \\
\text { Outer: } & \text { Silver Teflon }( \\
\end{array}$ & $\begin{array}{ll}\text { Inner: } & 0.14 / 0.05 \\
\text { Outer: } & 0.08 / 0.70 \\
\end{array}$ & {$[4]$} \\
\hline Sun Shield Layer \#2 & $\begin{array}{ll}\text { Inner: } & \text { VDA Kapton }{ }^{\circledR} \\
\text { Outer: } & \text { SV5 }\end{array}$ & $\begin{array}{ll}\text { Inner: } & 0.14 / 0.05 \\
\text { Outer: } 0.08 / 0.81\end{array}$ & {$[4]$} \\
\hline Sun Shield Layer \#3 & $\begin{array}{ll}\text { Inner: } & \text { VDA Kapton® } \\
\text { Outer: } & \text { SV5 }\end{array}$ & $\begin{array}{l}\text { Inner: } 0.14 / 0.05 \\
\text { Outer: } 0.08 / 0.81\end{array}$ & {$[4]$} \\
\hline
\end{tabular}

For the LH2 and GH2 tanks, aluminized Kapton® was also selected as the optical coating for the MLI outer surface. This was acceptable due to the fact that very little solar radiation impinges on the LH2 and GH2 tanks and, thus, a low absorptivity to emissivity $(\alpha / \varepsilon)$ ratio was not required for these surfaces. Conversely, for the $\mathrm{LO} 2$ and $\mathrm{GO} 2$ tanks, silver Teflon囚 was selected as the optical coating for the MLI outer surface. This was due to the fact that the LO2 and GO2 tanks are subjected to high amounts of solar radiation and, consequently, require an optical coating having a low $\alpha / \varepsilon$ ratio.

\footnotetext{
${ }^{7}$ Sun shield half cone angle and length are $60^{\circ}$ and 24.55 feet, respectively.

${ }^{8}$ This length is based on the assumption that the sun shield has a cone angle of $60^{\circ}$. 


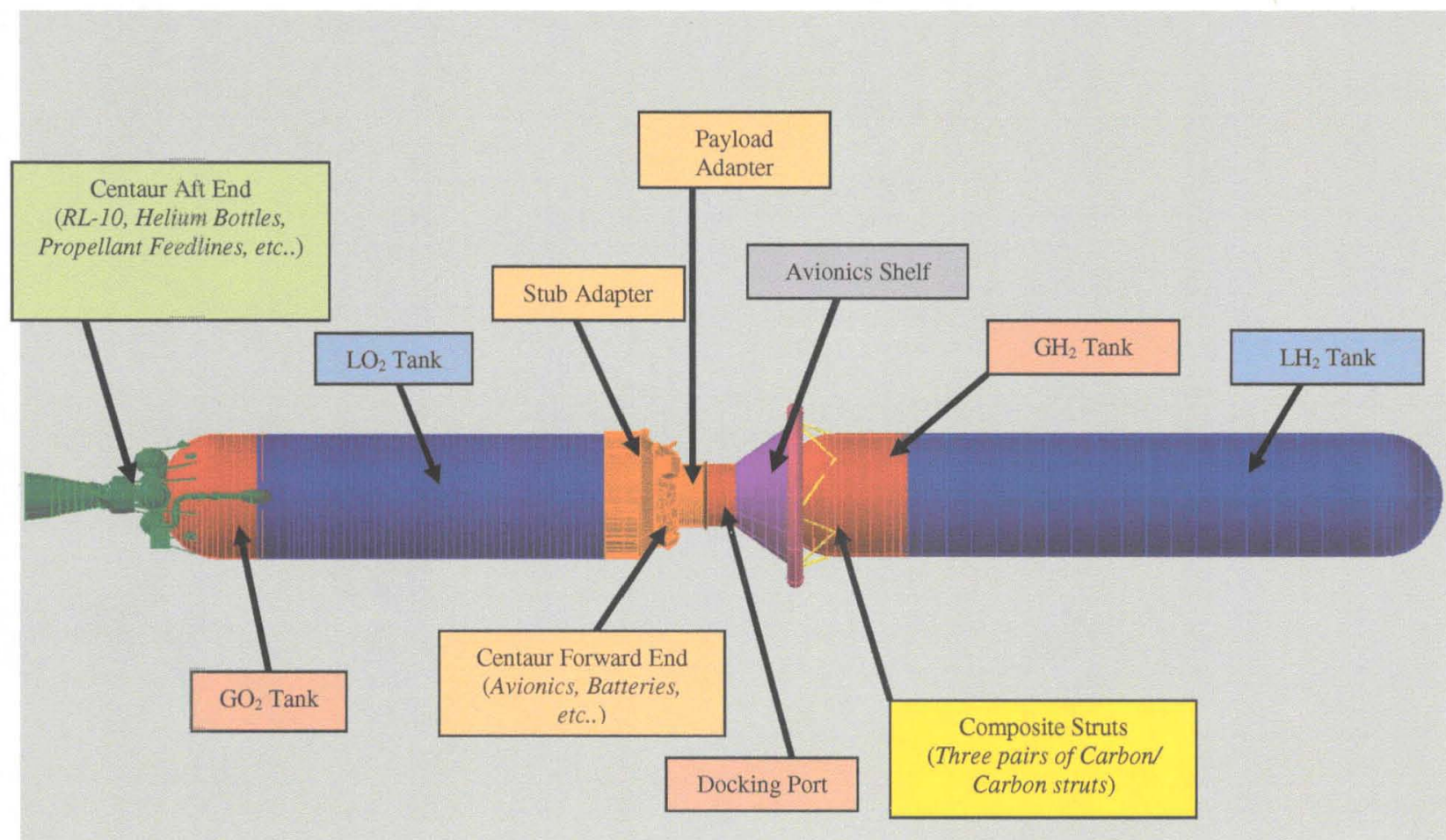

Figure 3. CPD Concept - Dual Propellant Configuration (Sun Shield Removed to Reveal Tank Detail)

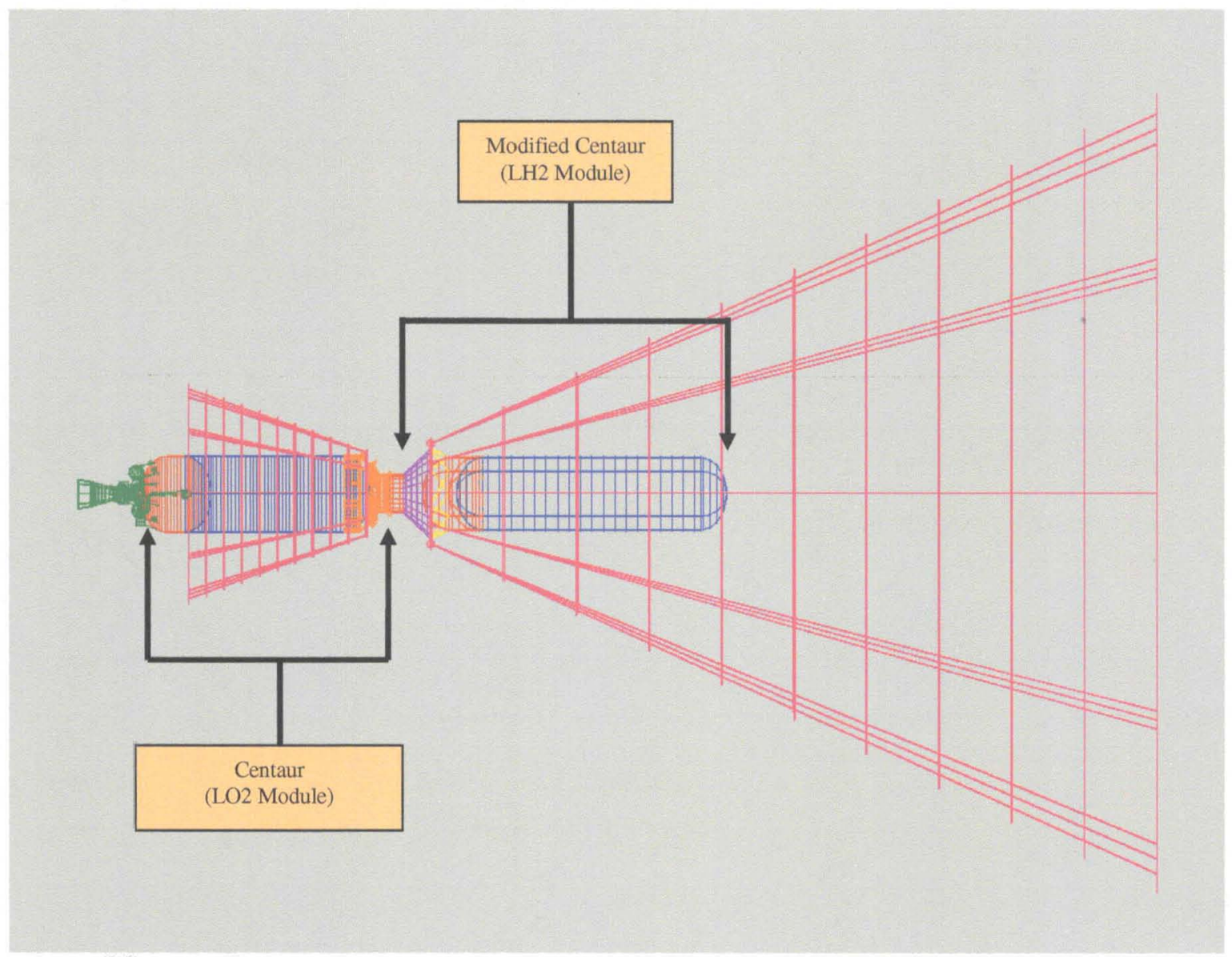

Figure 4. CPD Concept - Dual Propellant Configuration (Sun Shield Shown to Scale)

6

American Institute of Aeronautics and Astronautics 


\section{Cryogenic Propellant}

It was conservatively assumed in this analysis that the entire internal area of both the Centaur LO2 tank and modified Centaur LH2 tank are in constant contact with their cryogenic propellant. Further, it is assumed that the heat transfer coefficient between the tanks and cryogenic propellants is a uniform value of $0.75 \mathrm{BTU} / \mathrm{hr}-\mathrm{ft}^{2}-\mathrm{R}$, which is representative of a low gravity orbital environment. Table 3 contains the physical properties for the cryogenic propellants that were used in this analysis. The cryogenic propellants inside the tanks were modeled as constant temperature boundary nodes. It was conservatively assumed that the cryogenic propellants were already at saturation temperature when the CPD was inserted into LEO. Consequently, all heat absorbed by the propellants while on-orbit immediately contributed to the vaporization process (i.e., no heat required to first raise the propellant to the saturation temperature).

Table 3. CPD Cryogenic Fluid Saturation Properties

\begin{tabular}{|c|c|c|c|c|}
\hline Cryogenic Fluid & $\begin{array}{c}\text { Pressure } \\
(\text { PSI) }\end{array}$ & $\begin{array}{c}\text { Boundary Temperature } \\
(\mathbf{R})\end{array}$ & $\begin{array}{c}\text { Heat of Vaporization } \\
\text { (BTU/lbm) }\end{array}$ & Ref. \\
\hline LO2 & 35 & 180 & 87 & {$[3]$} \\
\hline GO2 & 35 & 180 & NA & {$[3]$} \\
\hline LH2 & 35 & 42.67 & 182 & {$[3]$} \\
\hline GH2 & 35 & 42.67 & NA & {$[3]$} \\
\hline
\end{tabular}

\section{Results}

Figure 5 through Fig. 7 summarize the predicted average heat leak rates entering the LH2 and LO2. The boil-off rates (\% per day) that are presented in Fig. 7 were calculated using the following formula:

$$
\text { Boil Off (\% per day) }=\frac{Q * 100}{H_{V} * 24 * M}
$$

where $M$ is the mass of the cryogenic propellant, $H_{V}$ is the heat of vaporization, and $Q$ is the average heat leak rate. The mass of the LH2 and the LO2 were assumed to be $5 \mathrm{mT}(11060 \mathrm{lbs})$ and $55 \mathrm{mT}(121660 \mathrm{lbs})$, respectively [8]. 


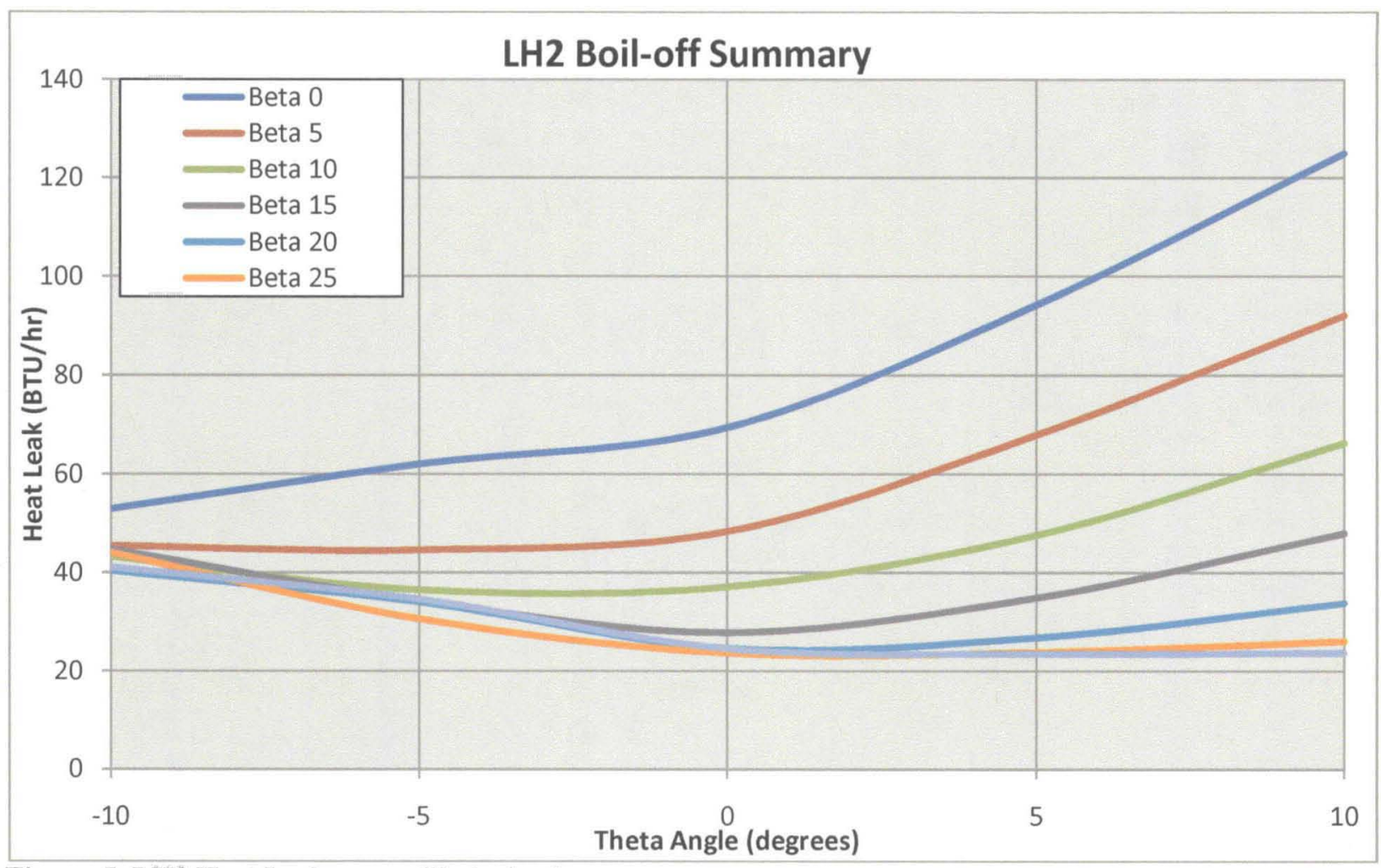

Figure 5. LH2 Heat Leak versus Theta Angle

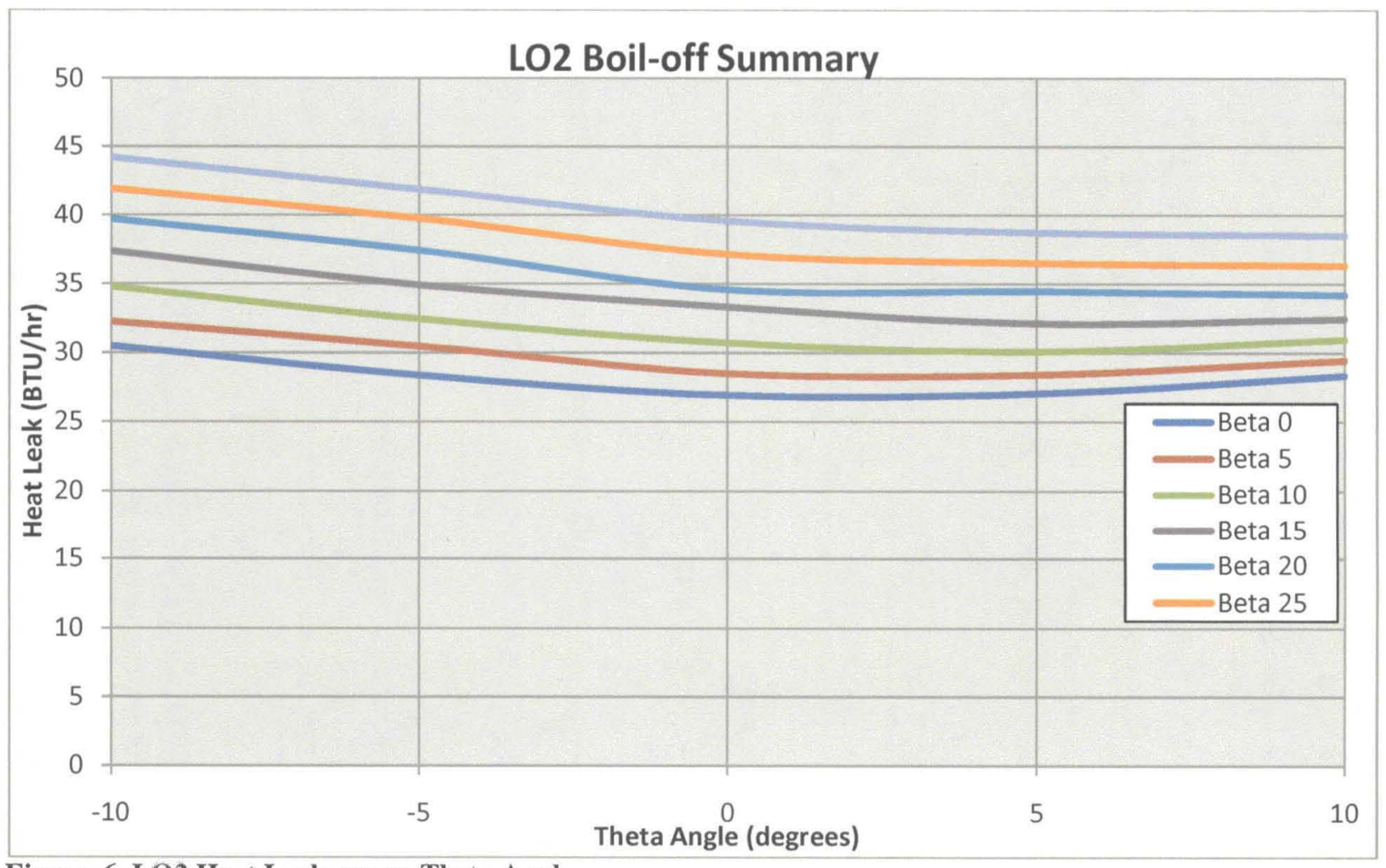

Figure 6. LO2 Heat Leak versus Theta Angle 


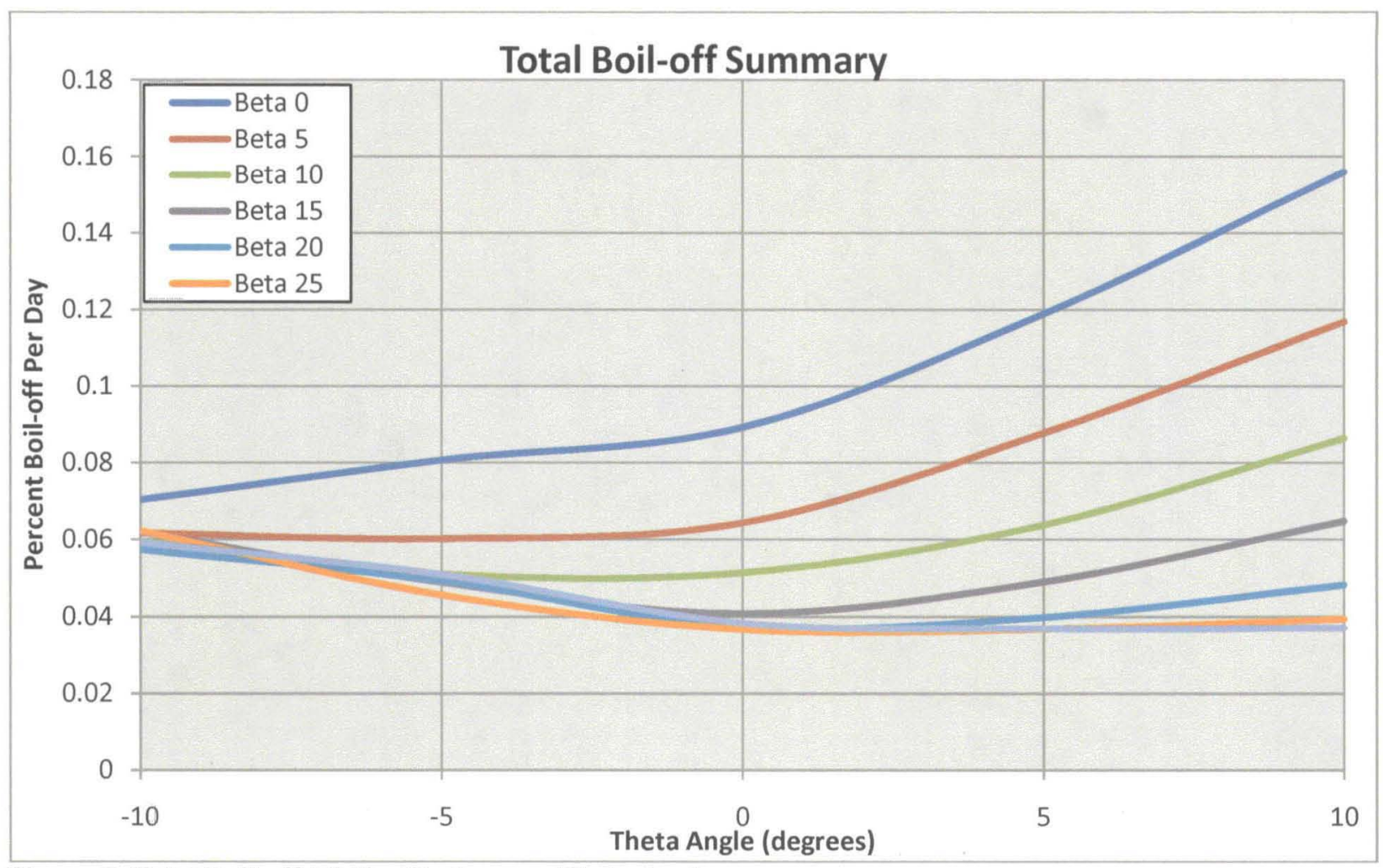

Figure 7. Total Boil-off (\% Per Day) versus Theta Angle

\section{Conclusion}

Figure 7 contains the summary of the total boil off (\% per day) for an on-orbit CPD. From Fig. 7, it is clear that the current CPD design has achieved the goal of a total boil off rate that is less than $0.05 \%$ per day. Figure 5 and Fig. 6 are also critical because it can determine if a certain CPD attitude (i.e. Beta, Theta) is desired based on a specific mission need to store one propellant longer/shorter than the other, or store both propellants at the same boil off rate.

From the results presented in this report, the optimal combination of CPD Beta and Theta angles for reducing LO2 boil-off is $0^{\circ}$ and $0^{\circ}$, respectively. Because of the reduced length of the Centaur sunshield, the LO2 tank has direct solar radiation impingement. At Beta and Theta equal to 0 , the direct solar radiation on the LO2 tank is minimal. The optimal combination of Beta and Theta with regards to reducing LH2 boil-off is $30^{\circ}$ and $5^{\circ}$, respectively. In Fig. 6, there were several observed trends. For a constant Theta, the heat leak entering the Centaur tends to increase as Beta increases. Conversely, for a constant Beta the heat leak entering the Centaur tends to decrease as Theta increases. These trends underscore the fact that the heat leak entering the LO2 tank was more sensitive to Beta than Theta. At Beta and Theta equal to zero, the LH2 module's sunshield is able to fully enclose the LH2 tank from any direct solar radiation. Therefore, the thermal environment inside the LH2 module sunshield is dominated by IR. However, because the CPD is composed of both the Centaur and the LH2 module, the overall lowest heat leak was for a Beta and Theta of $20^{\circ}$ and $0^{\circ}$, respectively. There were several trends observed in Fig. 5. For a constant Theta angle, the heat leak entering the LH2 module tends to decrease as Beta angle increases. Conversely, for a constant Beta, the heat leak entering the $\mathrm{LH} 2$ module tends to increase as Theta deviates from zero. 


\section{Acknowledgments}

This work has been funded and supported by NASA, Launch Services Program, through an advanced special studies contract. The authors would like to thank Paul A. Schallhorn ${ }^{9}$ for his invaluable advice and funding for the CPD special study. The authors also want to acknowledge $C \& R$ Tech $^{\mathrm{TM}}$ for their versatile software and professional assistance.

\section{References}

1. Unitèd Launch Alliance (2007). Atlas Familiarization. None

2. Kuttèr, Zegler, O'Neil, and Pitchford, "A Practical, Affordable Cryogenic Propellant Depot Based on ULA's Fight Experience", September 2009

3. Retrieved 07 29, 2010, from Thermophysical Properties of Fluid Systems: http://webbook.nist.gov/chemistry/fluid/

4. Gilmore G. David, Spacecraft Thermal Control Handbook: Volume I: Fundamental Technologies,EL Segundo, California: The Aerospace Corporation, 2002

5. Section 4 In-space Propellant Transfer and Storage Demonstration: Flagship Technology Demonstration, RFINNH10ZTT003L, June 10, 2010

6. ILC Dover Final Report, Phase II IR\&D-Centaur Sun Shield Development, December 18,2009.

7. United Launch Alliance, LLC. (10 June 2010). Section 4 In-Space Propellant Transfer and Storage Demonstration Flagship Technology Demonstration RFI-NNH10ZTT003L. Houston, TX: NASA / Johnson Space Center.

\footnotetext{
${ }^{9}$ NASA, Launch Services Program, Environments \& Launch Approval Branch Manager 


\section{Thermal Optimization and Assessment of a Long Duration Cryogenic Propellant Depot}

AIAA 50th Aerospace Sciences Conference

Prepared by Ryan Honour 


\section{Agenda}

- Problem Statement

- Introduction (CPD Concept)

- Development of the CPD ITM

- On Orbit Thermal Environment

- Geometric Math Model

- Results

- Conclusion

- Questions 
A Cryogenic Propellant Depot (CPD) operating in Low Earth Orbit (LEO) could provide many near term benefits to NASA space exploration efforts. These benefits include elongation/extension of spacecraft missions and reduction of launch vehicle up-mass requirements. Some of the challenges include controlling cryogenic propellant evaporation and managing the high costs and long schedules associated with new spacecraft hardware development. This presentation describes a conceptual CPD design that is thermally optimized to achieve extremely low propellant boil-off rates. The CPD design is based on existing launch vehicle architecture, and its thermal optimization is achieved using current passive thermal control technology. Results from an integrated thermal model are presented showing that this conceptual CPD design can achieve propellant boil-off rates well under $0.05 \%$ per day, even when subjected to the LEO thermal environment. 


\section{Intrc}

- The forward end of an Atlas V Centaur is mated to the aft end of a modified Atlas V Centaur.

- The modified Centaur would consist of an elongated LH2 tank connected to a small boil-off storage tank.

- Both the Centaur and modified Centaur would be encapsulated within the Atlas V 5 -meter payload fairing at launch.

- Once on orbit, residual LH2 within Centaur would be transferred to the modified Centaur; the residual $\mathrm{H} 2$ would be purged with Helium.

- The modified Centaur functions as the onorbit LH2 storage module, and the Centaur functions as the on-orbit LO2 storage module. ${ }^{1}$

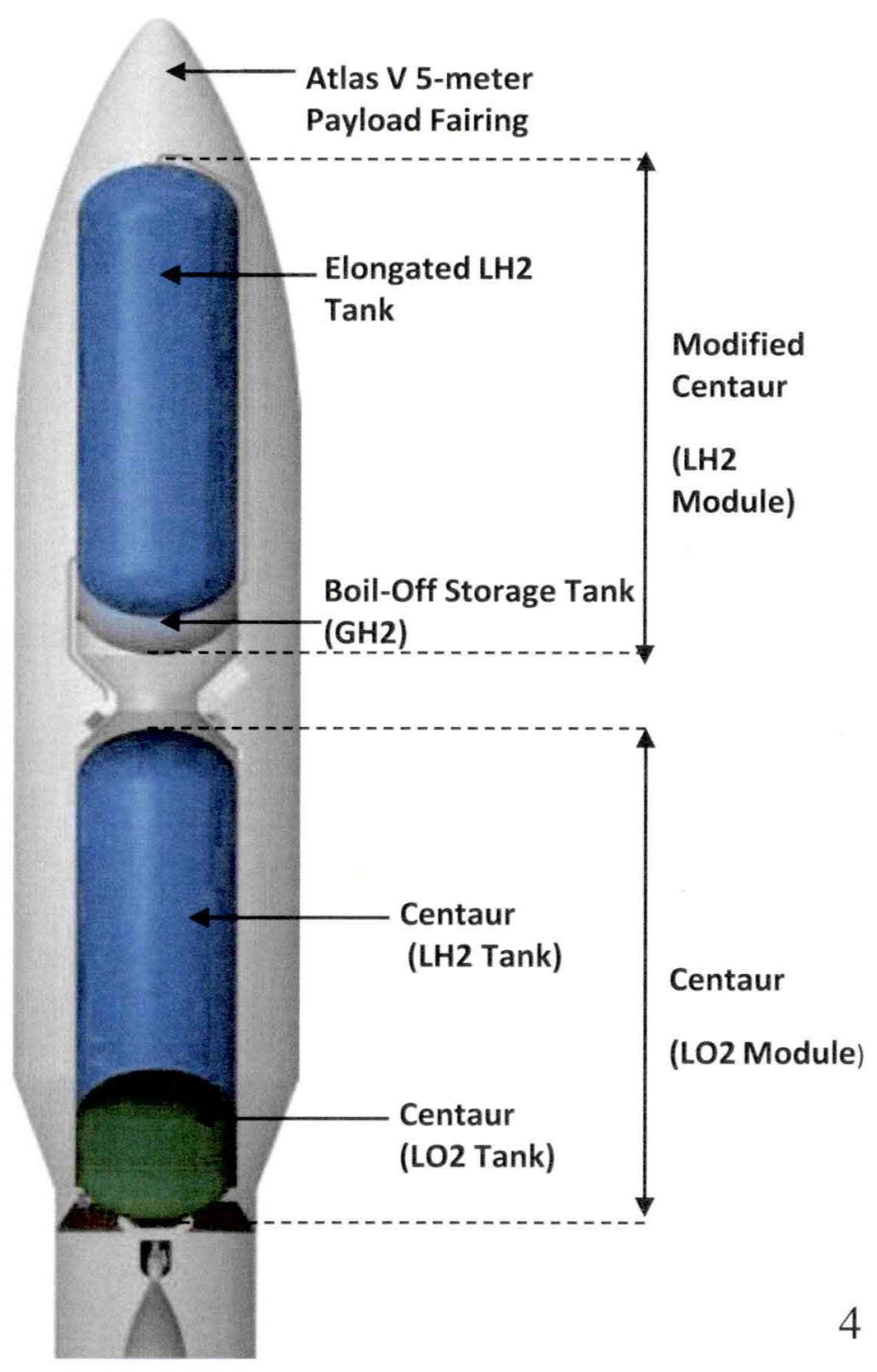




\section{Development of the CPD ITM}

- Thermal Desktop ${ }^{\mathrm{TM}}$ Version 5.3

- 18 discrete steady-state orbital positions.

- To simulate the on-orbit radiation exchange

- 5000 rays per node were shot to calculate the CPD radiation conductors (RadK's) and orbital heating rates (solar, earth IR and albedo)

- A sensitivity study determined that further increasing the number of rays and/or orbital positions had little effect on the fidelity of the solution.

- It is important to note that all predicted heating rates in this analysis represent orbital averages.

- Average from all eighteen orbital positions 


\section{On Orbit Thermal Environment}

- $\quad$ Altitude $(\mathrm{nm})$

- 365

- Beta Angle (degrees)

- $\quad 0-30$

- RAAN (degrees)

- 90

- $\quad$ Orbital Period (hr)

- 1.6378

- Orbital Eccentricity

$-\quad 0$

- Theta (degrees)

$-\quad-10-+10$

- $\quad$ Tracking

- + Z Solar

- $\quad$ Albedo

- 0.35

- $\quad$ Deep Space IR (deg R)

$-4$

- Solar Radiation (BTU/hr/ft $2 / \mathrm{F})$

- 429.2

- $\quad$ Earth IR (BTU/hr/ft²/ F)

- Illumination: 70.2

- Ellipse: 35.1

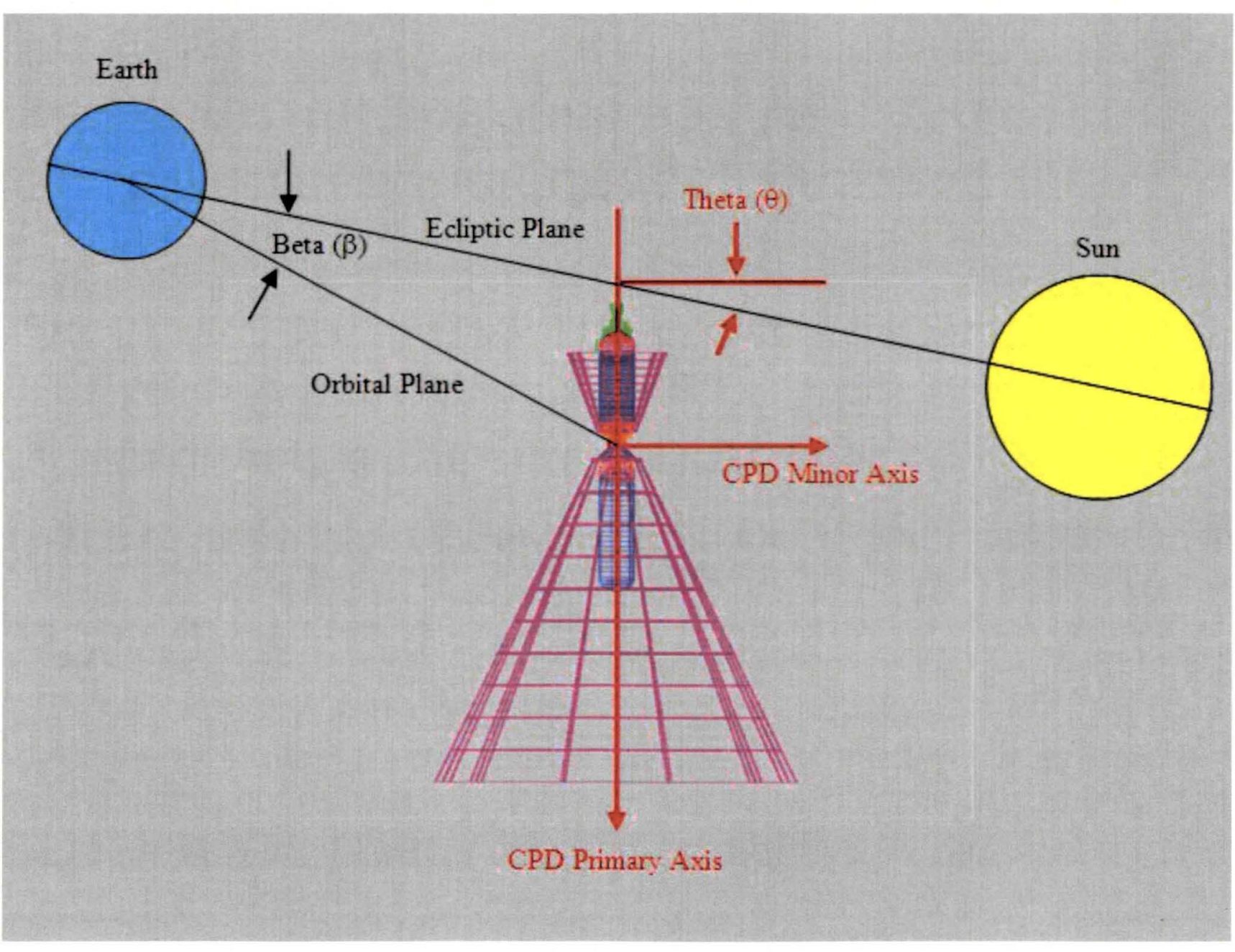


Thermal Optimization and Assessment of a Long Duration Cryogenic Propellant Depot

\section{Geometric Math Model}

CPD Concept - Dual Propellant Configuration

(Sun Shield Removed to Reveal Tank Detail)

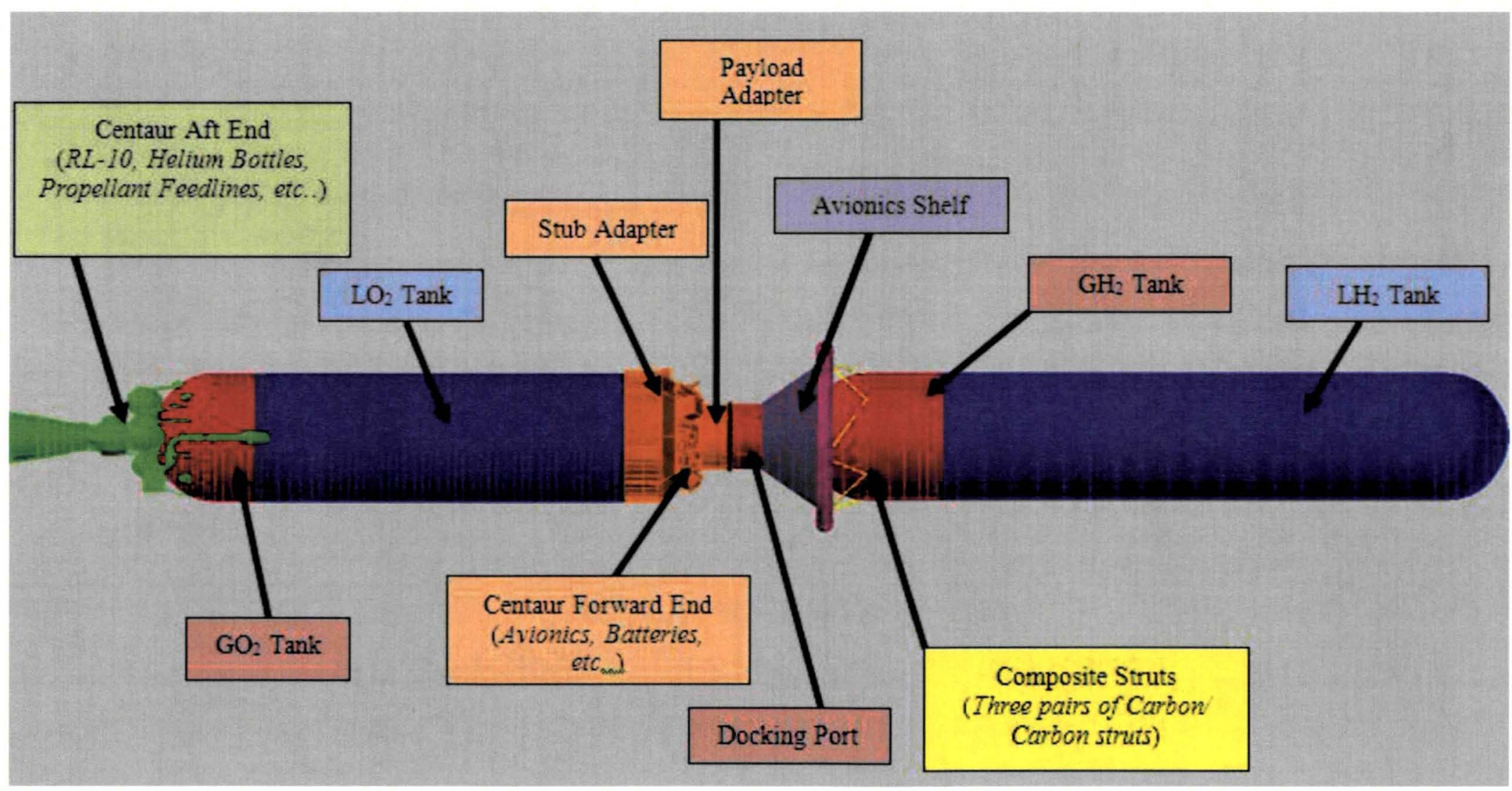

- All propellant tanks were enclosed in ten layers of MLI 
Thermal Optimization and Assessment of a Long Duration

Cryogenic Propellant Depot

\section{Geometric Math Model}

\section{CPD Concept - Dual Propellant Configuration}

(Sun Shield Shown to Scale)

\begin{tabular}{|l|l|l|}
\hline \multicolumn{1}{|c|}{$\begin{array}{c}\text { Structure/ } \\
\text { Equipment Item }\end{array}$} & $\begin{array}{c}\text { Absorptivity/ } \\
\text { Emissivity }\end{array}$ & Ref. \\
\hline Centaur Sun Shield & & \\
\hline Sun Shield Layer \#1 & $\begin{array}{c}\text { Inner: } 0.14 / 0.05 \\
\text { Outer: } 0.07 / 0.80\end{array}$ & {$[2]$} \\
\hline Sun Shield Layer \#2 & $\begin{array}{c}\text { Inner: } 0.14 / 0.05 \\
\text { Outer: } 0.08 / 0.81\end{array}$ & {$[2]$} \\
\hline Sun Shield Layer \#3 & $\begin{array}{l}\text { Inner: } 0.14 / 0.05 \\
\text { Outer: } 0.08 / 0.81\end{array}$ & {$[2]$} \\
\hline Primary Propellant Tank & & \\
\hline Sun Shield Layer \#1 & $\begin{array}{c}\text { Inner: } 0.14 / 0.05 \\
\text { Outer: } 0.08 / 0.70\end{array}$ & {$[2]$} \\
\hline Sun Shield Layer \#2 & $\begin{array}{c}\text { Inner: } 0.14 / 0.05 \\
\text { Outer: } 0.08 / 0.81\end{array}$ & {$[2]$} \\
\hline Sun Shield Layer \#3 & $\begin{array}{c}\text { Inner: } 0.14 / 0.05 \\
\text { Outer: } 0.08 / 0.81\end{array}$ & {$[2]$} \\
\hline
\end{tabular}

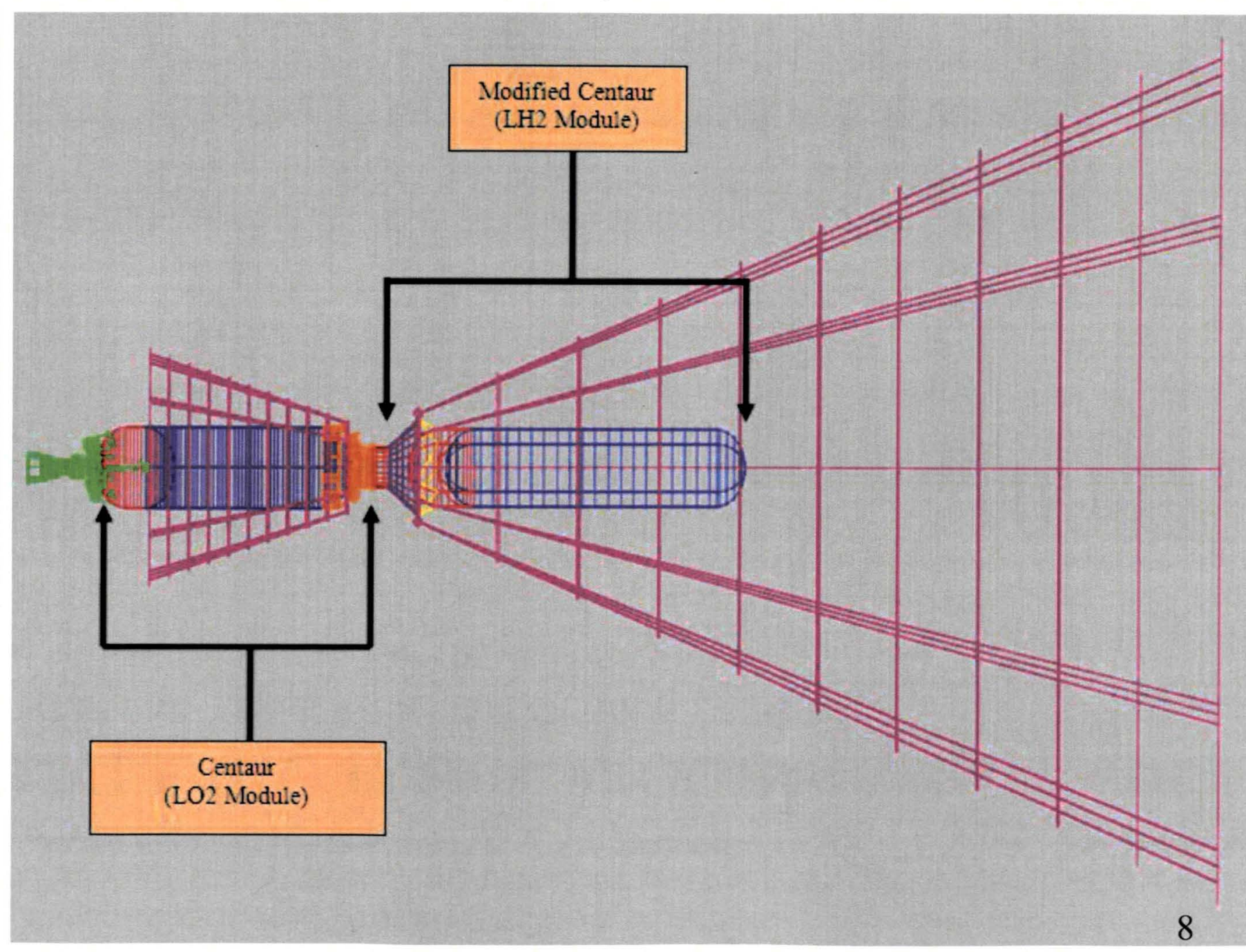


Thermal Optimization and Assessment of a Long Duration

Cryogenic Propellant Depot

\section{Results}

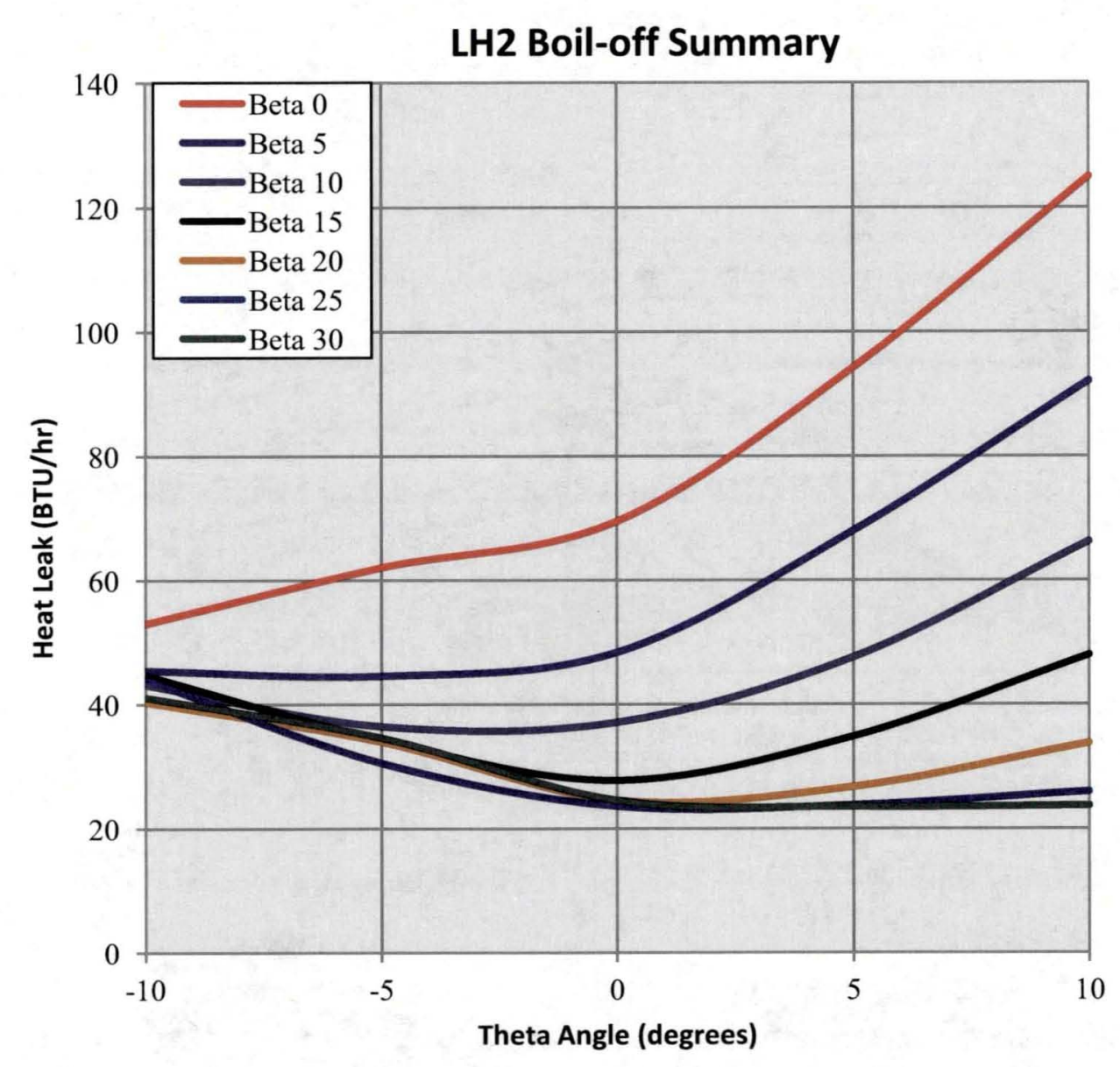

- Modified Centaur Optimal

Configuration

- Beta: $30^{\circ}$

- Theta: $5^{0}$

- Constant Theta, the heat leak entering the LH2 tank tends to decrease as Beta increases.

- Constant Beta, the heat leak entering the LH2 tank tends to increase as Theta increases. 
Thermal Optimization and Assessment of a Long Duration

Cryogenic Propellant Depot

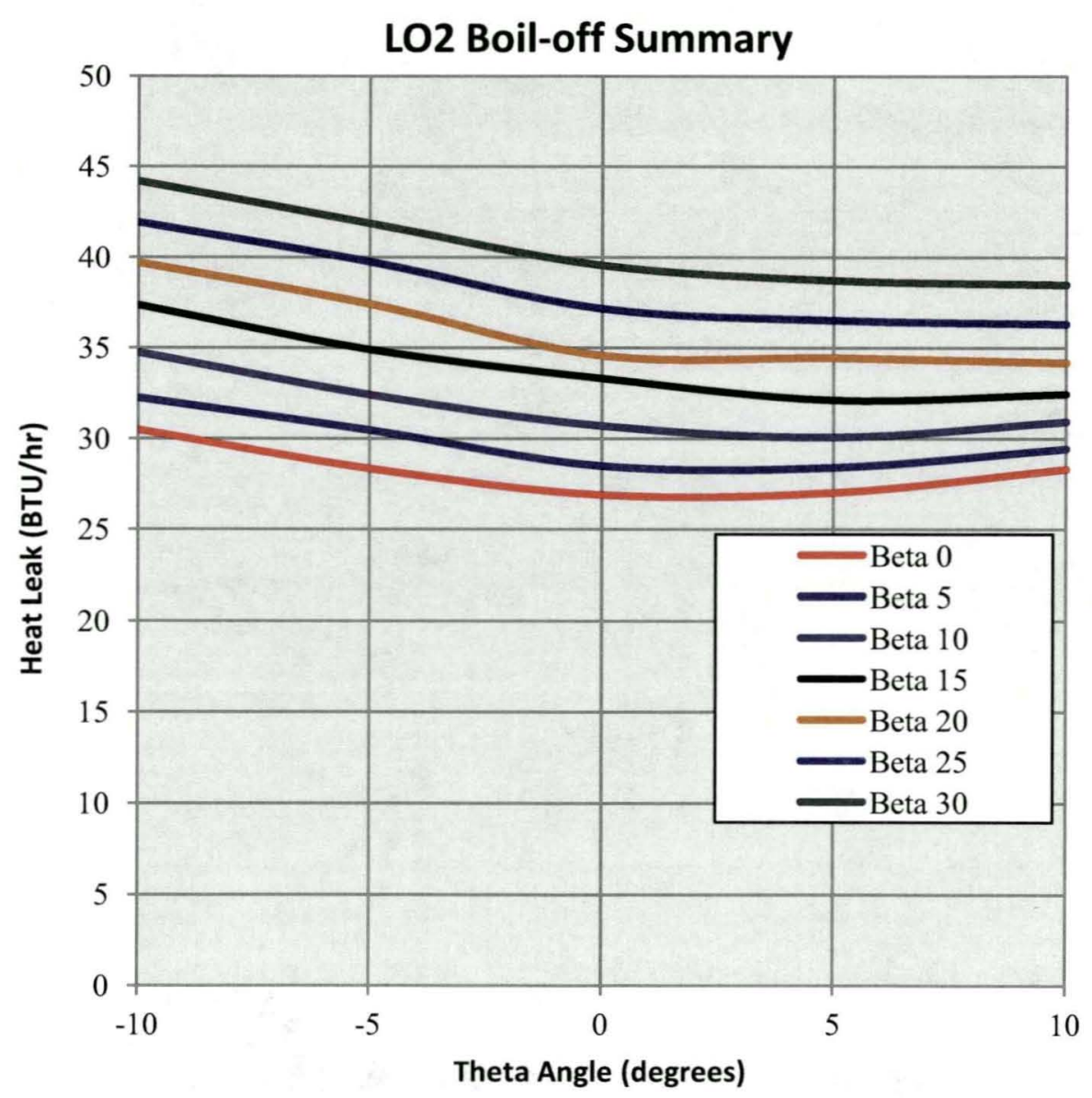

- Centaur Optimal Configuration

- Beta: $0^{0}$

- Theta: $0^{0}$

- Constant Theta, the heat leak entering the Centaur tends to increase as Beta increases.

- Constant Beta, the heat leak entering the Centaur tends to decrease as Theta increases. 
Thermal Optimization and Assessment of a Long Duration Cryogenic Propellant Depot

\section{Results}

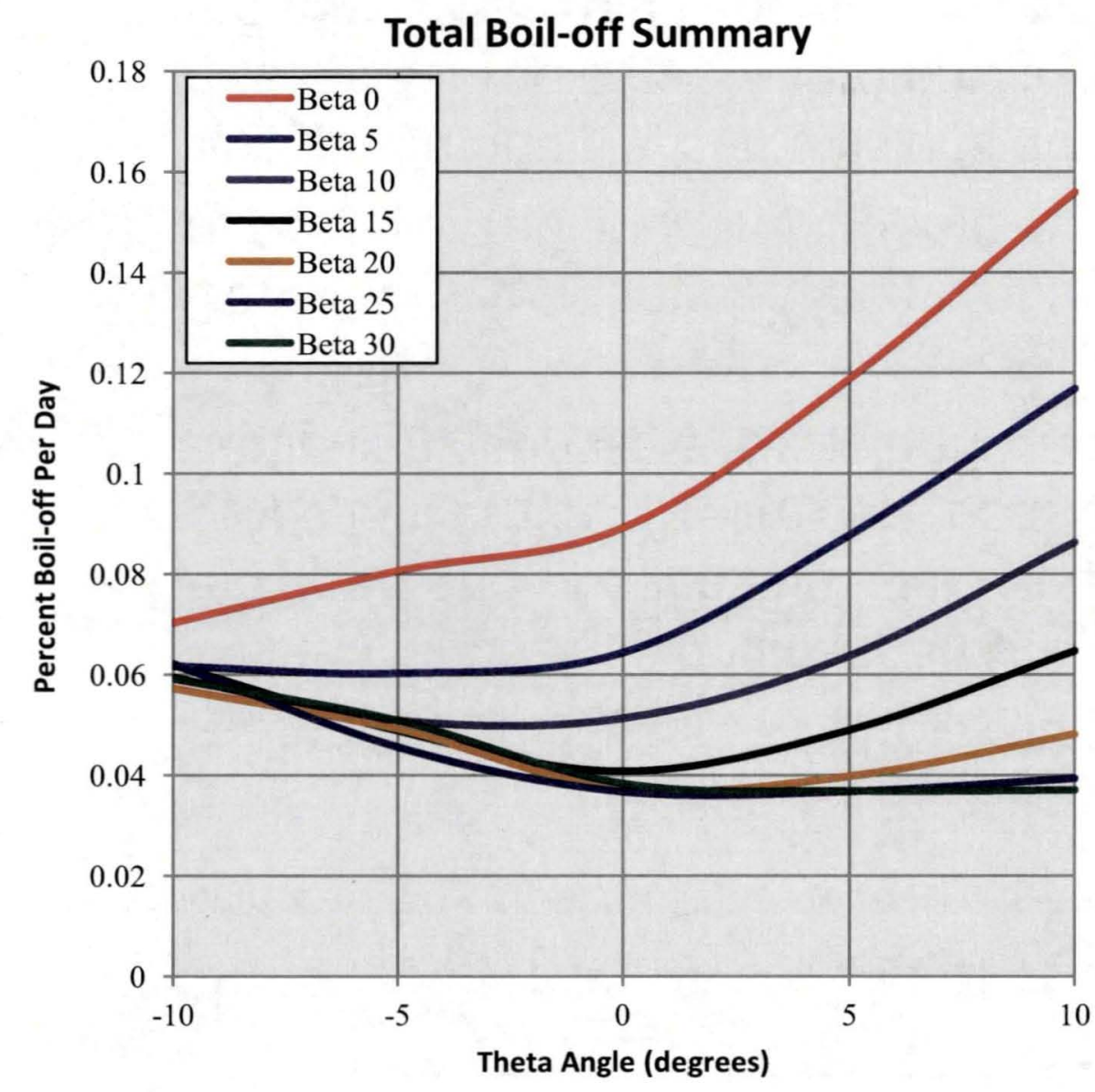

- Combined Optimal Configuration

- Beta: $20^{\circ}$

- Theta: $0^{0}$

Boil Off $(\%$ per day $)=\frac{\text { Average Heat Leak } * 100}{\text { Heat of Vaporization } * 24 * \text { Mass }}$ 


\section{Conclusion}

- Earth IR and Albedo can be problematic at any attitude. As both are emitted diffusely, significant amounts of earth IR and Albedo can traverse the open end of each sunshield and, subsequently, impinge upon the propellant tanks. Preliminary analysis suggested that the $\mathrm{LH} 2$ module was particularly sensitive to earth IR and Albedo during the illumination phase of the orbit.

- Because of the reduced length of the Centaur Sun shield, the LO2 tank has direct solar radiation impingement.

- The LH2 module's Sun shield is able to fully enclose the LH2 tank from any direct solar radiation. Therefore, the thermal environment inside the $\mathrm{LH} 2$ module Sun shield is dominated by IR.

- An overall boil-off (\% per day) of 0.05 is achievable. 
Thermal Optimization and Assessment of a Long Duration

Cryogenic Propellant Depot

\section{Questions?}




\section{References}

1. In-space Propellant Transfer and Storage Demonstration: Flagship Technology Demonstration, RFI-NNH10ZTT003L, June 10, 2010

2. Gilmore G. David, Spacecraft Thermal Control Handbook: Volume I: Fundamental Technologies, EL Segundo, California: The Aerospace Corporation, 2002

3. Thermophysical Properties of Fluid Systems: http://webbook.nist.gov/chemistry/fluid/ [cited 29 July 2010] 


\section{Back Up Slides}


Thermal Optimization and Assessment of a Long Duration

Cryogenic Propellant Depot

\section{CPD Cryogenic Fluid Saturation Properties}

\begin{tabular}{|c|c|c|c|c|}
\hline Cryogenic Fluid & $\begin{array}{c}\text { Pressure } \\
\text { (PSI) }\end{array}$ & $\begin{array}{c}\text { Boundary } \\
\text { Temperature } \\
(\mathbf{R})\end{array}$ & $\begin{array}{c}\text { Heat of Vaporization } \\
\text { (BTU//bm) }\end{array}$ & Ref. \\
\hline LO2 & 35 & 180 & 87 & {$[3]$} \\
\hline GO2 & 35 & 180 & NA & {$[3]$} \\
\hline LH2 & 35 & 42.67 & 182 & {$[3]$} \\
\hline GH2 & 35 & 42.67 & NA & {$[3]$} \\
\hline
\end{tabular}

